\title{
A TRAJETÓRIA DA VIOLÊNCIA DOMÉSTICA NO MUNICÍPIO DE RIBEIRÃO PRETO
}

Maria das Graças Carvalho Ferriani* Flávia Martinelli Pelegrino**

\section{Resumo}

O presente estudo tem como objetivo conhecer e caracterizar a trajetória dos casos de violência encaminhados do Centro de Referência da Criança e do Adolescente (CRCA) para o Centro de Atendimento à Criança e ao Adolescente Vitimizados (CACAV) no período de 1997 a 2001. A investigação ocorreu foi do tipo exploratória e descritiva. Do total de casos encaminhados para o CACAV $(n=731)$ $46,8 \%$ são do sexo feminino. A pesquisa ainda revelou que houve predominância nos casos de negligência com 35,7\%; diferentemente do que é encontrado na literatura. Concluímos que há necessidade de padronização de termos e a criação de instrumento de registros que permitem colher informações precisas acerca da violência contra crianças e adolescentes. Descritores: violência doméstica; denúncia; criança e adolescente vitimizados

\section{Abstract}

This study aims at learning and characterizing the path of violence cases referred from the Center of Reference of Children and Adolescents (CRCA) to the Center of Attention to Victimized Children and Adolescents (CACAV) between 1997 and 2001. The investigation performed was exploratory and descriptive. $46.8 \%$ of the cases referred to the CACAV $(n=731)$ involved women. The research also showed that there was prevalence in the cases of negligence, with 35.7\%, differently from what is found in literature. We have concluded that there is a need to standardize terms and create an instrument of recordkeeping that may allow the collection of accurate information on violence against children and adolescents.

Descriptors: domestic violence; denounce, victimized child and adolescent

Title: The path of domestic violence in the town of Ribeirão Preto

\section{Resumen}

El estudio presente tiene como objetivo conocer y caracterizar la trayectoria de los casos de violencia enviados del Centro de Referencia del Niño y del Adolescente (CRCA) al Centro de Asistencia al Niño y al Adolescente Víctimas (CACAV) en el periodo de 1997 a 2001. La investigación fue del tipo exploratorio $y$ descriptivo. Del total de casos enviados al CACAV ( $n=731), 46,8 \%$ son del sexo femenino. La investigación también reveló que hubo predominio en los casos de negligencia con 35,7\%; diferentemente que se encuentra en la literatura. Concluimos que hay necesidad de estandarización de términos y la creación de instrumento de registros que permitan obtener información precisa acerca de la violencia contra los niños y adolescentes.

Descriptores: violencia doméstica; denuncia; el niño y el adolescente como víctimas Título: La trayectoria de violencia doméstica en el distrito municipal de Ribeirão Preto

\section{Introdução}

A violência está de tal modo arraigada em cada um dos passos e gestos do homem moderno que não se pode deixar de indagar se ela é um fenômeno típico de nossa época, se é um traço essencial que individualiza nosso tempo. O viver em sociedade foi sempre um viver violento. Por mais que recuemos no tempo, a violência está sempre presente, seja nas civilizações antigas em que o infanticídio era considerado um meio para eliminar todos aqueles pequenos que por desgraça nasciam com defeitos físicos ${ }^{(1)}$.

Crianças eram mortas ou abandonadas para morrerem desnutridas ou devoradas por animais, por razões como: equilíbrio de sexos, medida econômica nos grandes flagelos, por não agüentarem longas caminhadas, por motivos religiosos, por ser direito do pai reconhecer ou não o direito de viver de seu filho. Com o século XVI as agressões e violências contra crianças se intensificaram. Nesta época, surgiram os "colégios" que abrigavam estudantes pobres e sem famílias, indesejados pela sociedade, submetendo-os aos piores maus tratos e humilhações deliberadas.

No entanto, o século XX foi apontado por pesquisadores como sendo o "século da criança", pois ela passa a ser notada , descrita e aceita (em termos) como fazendo parte da humanidade. É exaltada e a família responsabilizada por tudo de mau que Ihe aconteça. São ressaltados os cuidados maternos e a caracterização da infância como um período básico e fundamental da existência do homem ${ }^{(2)}$.

Entretanto, o fenômeno da violência não deixou de acontecer. E por violência se entende imediatamente uma relação assimétrica hierárquica de Poder com fins de dominação, exploração e opressão.

A conversão dos diferentes em desiguais e a desigualdade em relação entre superior e inferior [...] a ação que trata um ser humano não como sujeito, mas como uma coisa. Esta se caracteriza pela inércia, pela passividade e pelo silêncio de modo que quando a atividade e a fala de outrem são impedidas ou anuladas, há violência(3:33).

Assim decidimos adotar em nossa pesquisa a conceituação que defende violência doméstica contra criança e adolescentes representa todo o ato ou omissão praticado por pai, parentes ou responsáveis contra crianças e/ou adolescente que sendo capaz de causar dano físico, sexual e/ou psicológico à vitima - implica de um lado, numa transgressão do poder, dever de proteção do adulto e de outro, numa "coisificação da infância, isto é, numa negação do direito que os adolescentes e crianças têm de serem tratados como sujeitos e pessoas em condição peculiar de desenvolvimento"(4:32).

Dentre as formas de violência cometidas contra crianças e adolescentes destacamos:

\subsection{Violência Física}

caracteriza-se por qualquer ação única ou repetida, não acidental (ou intencional), perpetrada por um agente agressor adulto ou mais velho, que provoque dano físico à criança $u$ adolescente. Este dano, causado pelo ato abusivo, pode variar de lesão leve a conseqüências extremas como a morte ${ }^{(5: 177)}$.

\footnotetext{
* Enfermeira. Professora Titular do Departamento de Enfermagem Materno-Infantil e Saúde Pública da EERP/USP. **Graduanda do Curso de Enfermagem da EERP/USPBolsista de Iniciação Cientifica CNPq.

E-mail do autor: caroline@eerp.usp.br
} 


\subsection{Violência Sexua}

é todo ato ou jogo sexual, relação heterossexual ou homossexual, entre um ou mais adultos e uma criança menor de 18 anos, tendo por finalidade estimular sexualmente a criança ou utilizá-la para ou obter uma estimulação sexual sobre sua pessoa ou de outra $\operatorname{pessoa}^{(4: 53)}$.

\subsection{Violência Psicológica}

que se apresenta geralmente sob as formas de rejeitar, isolar, aterrorizar, ignorar, corromper, criar expectativas irreais ou extremadas ${ }^{(6: 168)}$

\subsection{Negligência}

atos de omissão que tem efeitos negativos [...] e representa uma falha em termos do desempenho dos deveres parentais, incluindo os de supervisão, alimentação e proteção(7:44)

Essas formas de violência trazem consigo conseqüências orgânicas como lesões cutâneas, oculares, viscerais, fraturas, queimaduras, lesões permanentes e até morte; como conseqüências psicológicas temos sentimentos de raiva, ansiedade, medo, dificuldades escolares e dificuldades em confiar no próximo. Além desses traumas há ainda conseqüências no âmbito sexual como o risco de contrair doenças sexualmente transmissíveis e possibilidades de gravidez. Os sentimentos gerados pela dor decorrentes das agressões são na maioria das vezes reprimidos, esquecidos, negados mas eles nunca desaparecem ${ }^{(8)}$. Nesse contexto crianças e adolescentes envolvidos em situações de abuso físico ou sexual, são sujeitos de direitos, conforme o estabelecido pelo Estatuto da Criança e do Adolescente (ECA), e que é dever da família, da comunidade, da sociedade em geral e do Poder Público assegurar, com absoluta prioridade, a efetivação dos direitos referentes à vida [...](Art. $\left.4^{\circ}\right)^{(9)}$.

A Convenção das Nações Unidas sobre os Direitos da Criança em seu artigo 19 coloca que: "a criança deve ser protegida contra todas as formas de violência física ou mental, abuso sexual, enquanto estiver sob custodia dos pais, do representante legal ou de qualquer outra pessoa responsáve por ela"(10). No município de Ribeirão Preto esta proteção mantêm-se estruturada em instituições que prestam assistência à criança e ao adolescente desde do nível primário ao terciário. Temos, então a Rede de Atendimento Integral à Criança e ao Adolescente (RAICA) que é baseado em um sistemas hierárquico de ações de acordo com o nível de assistência (nível primário, secundário e terciário) e funciona juntamente com a Prefeitura Municipal, Poder Judiaciário e o Ministério Público. A RAICA tem como objetivos gerais:

- garantir uma abordagem interdisciplinar nos diferentes níveis; - obter uma visão mais global possível dos problemas;

- levantar necessidade e buscar soluções tanto individual como coletivo (comunidade);

prestar atendimento à crianças e adolescentes de 0-18 anos incompletos;

possibilitar a integração e apoio de outras instituições e serviços, a exemplo das ONGs e conselhos tutelares".

A RAICA engloba o Centro de Referência da Criança e ao Adolescente (CRCA) uma serviço de nível secundário que presta atendimento com psicólogos e assistentes socais, busca soluções para a demanda e necessidades que requeiram abordagem mais especializada, disponibilizando de programas para a inserção das crianças e adolescentes denunciados ao Disque Criança, assim como para suas famílias. O Disque Criança é um instrumento que permite denunciar crianças e adolescentes que estão sendo vítimas de algum tipo de violência. Esta denúncia é feita por meio de uma ligação telefônica. Após a realização da denúncia as assistentes sociais da Secretária Municipal do Bem Estar Social são designadas para averiguar o caso e analisar o risco. Caso haja risco de vida para crianças e adolescentes, o Conselho Tutelar é acionado.

Constatado a necessidade de retirar a criança e/ou adolescente da responsabilidade da família, estes são encaminhados formalmente através do Conselho Tutelar e Juizado da Infância e da Juventude ao Centro de Atendimento a Criança e ao Adolescente Vitimizado (CACAV), instituição que se classifica como nível terciário, e que abriga crianças de 02 a 17 anos em condições de abandono, carentes de cuidados básicos, vítimas de abuso físico, emocional e sexual. Portanto, o CACAV tem como finalidade oferecer a criança e ao adolescente vitimizado um abrigo que atenda suas necessidades no sentido provisório, garantindo atendimento integral à saúde, estimular participação em atividades de vida diária e prática.

É importante lembrar aqui que a existência da hierarquização das ações de saúde em níveis de complexidade, ou seja, nível primário, secundário e terciário, é um dos princípios que norteiam a doutrina do Sistema único de Saúde (SUS) a fim de oferecer a uma determinada população todas as modalidades de assistência, bem como o acesso a todo tipo de tecnologia disponível, possibilitando um grau ótimo de resolutividade ${ }^{(11)}$. Considerando estes aspectos, temos interesse em ter como objeto de estudo nessa pesquisa as crianças e os adolescentes vitimizados que foram encaminhados do Centro de Referência para o CACAV.

\section{Objetivo}

Conhecer e caracterizar a trajetória dos casos encaminhados do Centro de Referência a Criança e ao Adolescente (CRCA) para o Centro de Atendimento à Criança e ao Adolescente Vitimizados (CACAV) no período de 1997 a 2001.

\section{Metodologia}

Após aprovação pelo Comitê de Ética da Escola de Enfermagem de Ribeirão Preto da Universidade de São Paulo iniciou-se a pesquisa proposta. Esta foi desenvolvida em Ribeirão Preto-SP, município com 471.111 habitantes, possuidor de um dos maiores centros comerciais do estado. Contempla uma ampla infra-estrutura onde se destaca o setor saúde com um dos maiores hospitais do país sendo pólo de referência para toda a região e outros estados.

A pesquisa se deu no enfoque descritivo exploratório tipo estudo de caso pois este tipo de estudo fornece o conhecimento aprofundado de uma realidade delimitada. Aqui, crianças e adolescentes vitimizados e denunciados formaram essa realidade delimitada ${ }^{(12)}$. A investigação ocorreu no período de maio a junho de 2002 no CRCA. Todos os casos denunciados ao Disque Criança são registrados em um livro que é denominado de Cadastro de Atendimento Básico (CAB) que é preenchido por um técnico. Este livro contém o nome da criança denunciada, natureza do caso, encaminhamento e a assinatura do técnico responsável.

Os dados foram coletados através do registro deste livro e estabeleceu-se como critérios inclusivos os casos que chegassem ao Centro de Referência pelo Disque Criança e fossem encaminhados para o CACAV, no período de 1997 a 2001. Assim, obtivemos uma população de 731 individuos, entre crianças e adolescentes, de ambos os sexos. Posteriormente estes dados foram tabulados em um banco utilizando o programa Acess e Excel 98 e analisados quantitativamente quanto a encaminhamento dos casos, distribuição anual dos casos, sexo e natureza do caso.

\section{Resultados e discussões dos dados}

Neste período Ribeirão Preto registrou 7207 denuncias contra crianças e adolescentes. Observamos que desse montante $10 \%(n=731)$ foram encaminhados ao CACAV e que 90\% dos casos obtiveram resolução no próprio CRCA.

Fica evidente que grande parte dos casos denunciados 
necessitaram de uma resolução em nível primário e/ou secundário, representado aqui pelo CRCA que possui programas de apoio familiar e individual além de campanhas de prevenção contra violência infantil. Essas ações oferecidas pelo CRCA estão estabelecidos na RAICA (Rede de Atendimento Integral a Criança e Adolescente) que preconiza buscar soluções tanto no individual como no coletivo; ou seja; representados aqui, respectivamente, pela criança/adolescente vitimizados e sua família. Portanto, a incapacidade desses programas de suprir as necessidades imediatas/mediatas do processo de denúncia que envolve crianças e adolescentes acaba refletindo no encaminhamento dos casos para um outro nível, o terciário. Assim o CACAV, que é uma instituição de nível terciário, recebe uma pequena parcela do total desses casos.

Analisando a distribuição anual dos casos no período estudado, constatamos que os registros de denúncias se manteve equilibrada ao longo do período mas no ano 1999 ocorreu queda no número dos casos encaminhados, o que podemos estar relacionando com o melhor funcionamento dos programas de apoio oferecidos no nível primário e secundário colaborando dessa forma para a prevenção da violência contra crianças e adolescentes.

Outro fato que pode ter contribuído para a diminuição no número de casos denunciados em 1999 é o processo de denuncia. É necessário ressaltar que o ato de denunciar envolve muitos fatores, dentre eles, as famílias que podem desejar ou tentar impedir a notificação, podem fornecer ou negar informações que fundamentem as suspeitas, podem sentir-se ameaçadas ou protegidas pelo ato de notificar. Pesquisadores chamam a atenção para o fato de tratar-se de um fenômeno quase sempre criminalizável, envolvendo medo, vergonha e culpa ${ }^{(4)}$

Em relação ao sexo, constatamos que as meninas corresponderam a $46,8 \%$ do conjunto de ocorrências e foram o alvo principal da violência. Os meninos representaram $42,9 \%$. Houve $10,3 \%$ de casos em que não havia informações acerca do sexo. Ainda analisando a sua distribuição ao longo dos anos, o sexo feminino foi predominante entre as ocorrências, no entanto observamos que durante ano de 1997 o quadro se inverteu, ou seja, houve mais ocorrências de denúncias entre o sexo masculino (122 casos) do que o feminino (102 casos).

Estudos revelam que há um ligeiro predomínio do sexo feminino na distribuição do abusos ${ }^{(13)}$. No entanto, observaram que o sexo não é uma variável que determina a ocorrência de maus-tratos em geral, entre crianças e adolescentes ${ }^{(14)}$

Uma outra característica que os dados nos fornecem é a respeito da natureza do caso. Assim como foi definido inicialmente, temos as categorias de: violência sexual, violência física, violência psicológica e negligência. No entanto, no livro de registro - CAB - existe a utilização de outros termos para designar a natureza do caso. Dentre eles, temos:"criança perdida, criança de rua, fuga do lar, família carente, guarda da criança e pais presos ou dependentes químicos ou hospitalizados". Estes termos serão englobados em uma única categoria definida como: outros.

Tabela - Distribuição dos casos encaminhados ao CACAV segundo natureza do caso e período de 1997 a 2001.

\begin{tabular}{|c|c|c|c|c|c|c|}
\hline Natureza do caso Ano & 1997 & 1998 & 1999 & 2000 & 2001 & $\begin{array}{c}\text { TOTAL/ } \\
\text { Freqüência }\end{array}$ \\
\hline Violência física & 89 & 50 & 12 & 17 & 23 & $191(26,1 \%)$ \\
\hline Violência sexual & 30 & 4 & 1 & 1 & 9 & $45(6,2 \%)$ \\
\hline Violência psicológica & 7 & 2 & 0 & 5 & 3 & $17(2,3 \%)$ \\
\hline Negligência & 58 & 62 & 24 & 47 & 70 & $261(35,7 \%)$ \\
\hline Outros & 45 & 19 & 57 & 63 & 33 & $217(29,7 \%)$ \\
\hline TOTAL & 229 & 137 & 94 & 133 & 138 & $731(100 \%)$ \\
\hline
\end{tabular}

Fonte: Centro de Atendimento Básico, 2001

Uma investigação realizada em Campinas-SP referente aos atendimentos de um Centro de Atenção à Violência Doméstica, no período de 1988-1992, comprovou que a violência física ocorreu em $43,1 \%$ dos casos atendidos. O abandono/ negligência foi responsável por $23,5 \%$ dos casos confirmados, a violência psicológica por $16,4 \%$ e a sexual por $7,7 \%{ }^{(5)}$.

Porém, o presente estudo revelou uma ordem diferente das manifestações de violência, conforme a tabela, houve predominância de negligência entre os casos estudados com $35,7 \%$; a categoria outros vem em segundo lugar com $29,7 \%$; em seguida temos: violência física com $26,1 \%$; violência sexual com $6,2 \%$ e por fim a violência psicológica com $2,3 \%$. Contudo, ao analisarmos estes mesmos dados mas na sua distribuição anual, verificamos que esta ordem não foi uma constante, pois, dentre os cinco anos estudados a categoria negligência e outros predominaram em dois anos, e violência física predominou somente em um ano.

Esta distribuição não constante dos tipos de violência acometidos contra criança e adolescentes pode estar relacionado com a utilização de termos ambíguos pelos vários técnicos que preenchem o Cadastro de Atendimento Básico (CAB), representando assim uma dificuldade de classificar os tipos de violência e consequentemente alterando a freqüência com que estes tipos se apresentam. Neste sentido, pesquisadores trazem que a questão da violência contra crianças e adolescentes - ao nível nacional e internacional revela a utilização indiscriminada de termos, alguns mais, outros menos populares. Enfim, todas essas dificuldades tem como conseqüência o fato de as definições permitirem identificar o fenômeno da violência doméstica contra criança e adolescente de forma inequívoca, porque dependem de definições legais ou variam com a sensibilidade de cada cultura ou ainda podem ser mistificados(4).

\section{Conclusão}

A trajetória dos casos de violência contra crianças e adolescentes no município de Ribeirão Preto fica evidenciado no estudo que grande parte dos casos permaneceram no CRCA; a nível primário/secundário; e apenas uma pequena parcela necessitaram de um atendimento a nível terciário 
(CACAV) e que destes, a maioria são do sexo feminino e tem a negligência como sua forma principal de ocorrência da violência. Embora estes dados apontam que a maioria dos casos obtém resolutividade a nível primário/secundário, devemos ressaltar a má qualidade dos registros de denúncias, principalmente no que se refere a descrição da vítima informações do tipo idade não é mencionada. Outro ponto que a pesquisa nos indica é que há a utilização de uma ampla terminologia por quem anota a ocorrência do tipo de violência acometida contra crianças e adolescentes, baseando-se muitas vezes na interpretação pessoal do caso em questão, tornando-se desse modo um dado subjetivo.

Diante desse quadro é necessário que os profissionais inseridos nos programas oferecidos pelo CRCA sejam mais preparados sobre a questão e que haja estudos que direcionem para a descrição, indicação e objetivos desses programas, pois, é este o local onde se retém a resolutividade da maioria dos casos de violência contra crianças e adolescentes. A utilização de uma padronização da terminologia e a criação e adoção de um instrumento de registros com dados suficientes com o auxílio de recursos tecnológicos para que consigamos o estabelecimento de estatísticas mais aprofundadas sobre este fenômeno, uma vez que elas, por maiores que sejam as dificuldades que possam apresentar, orienta-nos no estabelecimento de políticas de atendimento compatíveis ao fenômeno aqui estudado.

Apesar de alguns empecilhos encontrados há que se ressaltar a importância do envolvimento do profissional de saúde na questão da violência, pois, este se encontra inserido nos diversos níveis de hierarquização do sistema de saúde. O treinamento de recursos humanos é uma estratégia que permite atender a necessidade da instituição e também do profissional envolvido na questão, que traz como conseqüência a melhoria da assistência prestada e a qualificação que irá fundamentar o trabalho desenvolvido por estes profissionais.

A consciência e o reconhecimento de que crianças e adolescentes sofrem violência trouxe como conseqüência a necessidade de notificar o que implica em deveres para os profissionais de saúde. Assim, como está assegurado no artigo 245 do $E C A^{(10)}$, a não notificação à autoridade competente de caso suspeito ou de confirmação de maus tratos com a criança ou ao adolescente, por parte dos profissionais de saúde passa a ser considerado infração administrativa passível de multa.
Assim, julgamos que o profissional de saúde esclarecido com a temática aqui abordada, cumprirá com sua responsabilidade profissional, legal e moral e encontrará formas mais adequadas para interromper o círculo vicioso da violência.

\section{Referências}

1. Ariés P. História social da criança e da família. $2^{\mathrm{a}}$ ed. Rio de Janeiro: Atlas; 1981. 279p.

2. Krymski S. A criança maltratada. São Paulo: Almed; 1985. 178p.

3. Chauí M. Participando do debate sobre mulher e violência. In: Perspectivas Antropológicas da mulher. Rio de Janeiro: Zahar; 1985. 23p.

4. Azevedo MA, Guerra VA. A violência doméstica na infância e na adolescência. São Paulo: Robe; 1995. 126p.

5. Deslandes SF. Atenção a crianças e adolescentes vítimas de violência doméstica: análise de um serviço. Cadernos de Saúde Pública, Rio de Janeiro, 1999;10(supl1):177.

6. Minayo MCS. Violência contra crianças e adolescentes: questão social, questão de saúde. Rev Bras Saúde Mater Infant, São Paulo 2001 maio/ago; 2(1):91-102.

7. Giovannoni JM. Parental mistreatment perpetrators and victims. Journal of Marriage and the Family, New York 1971 Oct;33:649-657.

8. Greven NP. Sparae the Child. New York: Vintage Books; 1992. 55p.

9. Estatuto da Criança e do Adolescente. Brasília (DF): Centro Gráfico do Senado Federal; 1989. 51p.

10. Organização das Nações Unidas. Convenção sobre os direitos da criança. New York; 1989. 33p.

11. Santini LA. A saúde no município: Organização e Gestão. $2^{\mathrm{a}}$ ed. Rio de Janeiro: IBAM- UNICEF; 2001. 25p.

12. Triviños AN. Introdução à pesquisa em ciências sociais: A pesquisa qualitativa em educação. $3^{a}$ ed. São Paulo: Atlas; 1992. 175p.

13. Cavalcanti MLT. Estudo descritivo dos registros de violência doméstica no Conselho Tutelar de Niterói (RJ). Cadernos de Saúde Coletiva, Rio de Janeiro 1999 jan/jun;7(1): 99-123.

14. Cunha JM. Atendimento às crianças e adolescentes vítimas de violência doméstica: impasses e desafios [dissertação de Mestrado]. Rio de Janeiro: Fundação Oswaldo Cruz; 1992. 169 f.

Data de Recebimento: 07/03/2003

Data de Aprovação: 24/08/2004 